\title{
Article \\ Direct Self-Assembly of Hierarchically Grown Rhodium Thin Films for Electrocatalytic Hydrogen Evolution Reaction
}

\author{
Muhammad Ali Ehsan ${ }^{1}$, Alaaldin Adam ${ }^{1}$, Abdul Rehman ${ }^{2}$ and Mohammad Qamar ${ }^{1, *(D)}$ \\ 1 Center of Research Excellence in Nanotechnology (CENT), King Fahd University of Petroleum and Minerals, \\ Dhahran 31261, Saudi Arabia; meali@kfupm.edu.sa (M.A.E.); aaladinadam@kfupm.edu.sa (A.A.) \\ 2 Department of Chemistry, King Fahd University of Petroleum and Minerals, Dhahran 31261, Saudi Arabia; \\ abrehman@kfupm.edu.sa \\ * Correspondence: qamar@kfupm.edu.sa; Tel.: +966-013-860-97775
}

check for

updates

Citation: Ehsan, M.A.; Adam, A.;

Rehman, A.; Qamar, M. Direct

Self-Assembly of Hierarchically

Grown Rhodium Thin Films for

Electrocatalytic Hydrogen Evolution

Reaction. Catalysts 2021, 11, 338.

https://doi.org/10.3390/catal

11030338

Academic Editor:

Giuseppina Iervolino

Received: 18 February 2021

Accepted: 3 March 2021

Published: 6 March 2021

Publisher's Note: MDPI stays neutral with regard to jurisdictional claims in published maps and institutional affiliations.

Copyright: (c) 2021 by the authors. Licensee MDPI, Basel, Switzerland. This article is an open access article distributed under the terms and conditions of the Creative Commons Attribution (CC BY) license (https:/ / creativecommons.org/licenses/by/ $4.0 /)$.

\begin{abstract}
Thin films of metallic rhodium (Rh) are developed on two different supports, nickel foam (NF) and titanium foil (Ti), and evaluated for electrochemical hydrogen evolution reaction (HER). The electrodes are prepared by aerosol-assisted chemical vapor deposition technique using a $\mathrm{Rh}$ diethyldithiocarabamte precursor for three distinct time periods of 40,80 , and $120 \mathrm{~min}$ at $500{ }^{\circ} \mathrm{C}$. The film consists of phase pure metallic Rh with hierarchical flower-like morphology. The structural features of such nanostructures can be modulated by adjusting the growth time. The HER catalytic performance data for the optimized films (i.e., with the deposition time of $80 \mathrm{~min}$ ) suggest that the $\mathrm{Rh}$ deposited on Ti foil (Rh/Ti) catalyze the reaction substantially faster than Rh deposited on Ni foam (Rh/NF). To produce current density of $100 \mathrm{~mA} \mathrm{~cm}^{-2}$, the Rh/NF needed over potential of $263 \mathrm{mV}$, while the $\mathrm{Rh} / \mathrm{Ti}$ electrode required only $175 \mathrm{mV}$. In spite of lower electrical conductivity, caused by the bare Ti foil, the Rh/Ti electrode exhibits superior HER performance. The Tafel slopes of Rh/NF and $\mathrm{Rh} / \mathrm{Ti}$ electrodes are determined to be 52 and $42 \mathrm{mV} \mathrm{dec}^{-1}$, while the turnover frequencies are estimated to be 1.1 and $37.3 \mathrm{~s}^{-1}$ at over potential of $260 \mathrm{mV}$.
\end{abstract}

Keywords: energy conversion; $\mathrm{H}_{2}$ production; rhodium; thin films; water electrolysis

\section{Introduction}

Hydrogen holds a prominent position in clean energy assets with a potential to meet growing energy demands of the world while assuring a healthier and safer environment for the globe [1,2]. The extraction of hydrogen through electrochemical water splitting has been of practical interest as the process qualifies this clean and renewable energy criteria at fairly economical levels [3]. To serve this purpose, a variety of nanomaterials including low cost transition metals [4-6], alloys [7,8], and carbonaceous species [9] have been engineered to catalyze the hydrogen evolution reaction (HER). However, most of these evaluated materials have their performance lagging far behind the noble metals-based benchmark HER catalysts. Pt-group metals (i.e., platinum, ruthenium, and iridium), for instance, intrinsically possess superior electrocatalytic properties and exhibit excellent HER performance $[10,11]$. However, the scarcity and the high cost of these metals represent the major limiting factors for the commercial practices of hydrogen production. Reduced mass loadings and composite compositions are the most common among the strategies proposed in order to alleviate this cost issue [12-14]. Such measures [15-20] encompass downsizing the metal content in the final product via single atom strategies, anchoring the atoms on porous and conductive carbon-substrates, and forming their alloys or the hybridized structures with multiple different transition metals, preferably the inexpensive ones [21-23]. Interface and surface engineering strategies have also been employed to enhance cost-effectiveness and stability [24-26].

Instead of using discrete nanoparticles, deployment of noble metals in the form of nanostructured thin films in an economical fashion is a more feasible tool in the use of 
platinum group metals, especially the rhodium. This approach can avoid the use of highsurface area carbons supports which are usually required to use these discrete nanoparticles. A proper deposition protocol, however, for such a deployment is a critical component. We have recently demonstrated this notion for $\mathrm{Pd}$ and $\mathrm{Pt}$ thin films, indicating that a controlled fine-tuning of the structure driven by the film dimensionality is catalytically compelling to overcome the sluggish kinetics of the HER [27,28]. For these studies, we utilized aerosol-assisted chemical vapor deposition (AACVD) to fabricate homogeneous single-phase metallic films with very low metal loadings and sufficiently high electrocatalytic activity to suit commercial needs. Following the same route, we fabricated rhodium (Rh) thin films with low metal loadings to catalyze the HER reaction, thereby attempting to reduce the overall cost while still providing the inherent interaction mechanisms. Because of its excellent catalytic activities in many industrially relevant applications [29], such as hydrogenation [30,31], (NO)x abatement [32,33], C-C cross-coupling reaction [34], and oxidation [35,36], Rh is hypothesized to demonstrate an excellent performance in HER as well. Furthermore, due to its apex resistivity towards acids and bases, its tolerance against harsh reaction environments, and its high melting point, Rh metal is rendered broadly applicable for the phenomena that are potentially affected by aging of the materials [37]. For these reasons, Rh catalysts are applied in fuel cells for the production of CO-free hydrogen, [38,39] and automobile catalytic converters [40]. Rh electrodes and membrane filter materials have also been utilized in gas sensors [41,42]. Because of all these application attributes, we hypothesized that the pure phase of Rh films can drive the HER in a facile way.

Both chemical and physical vapor deposition approaches have been implemented for the fabrication of metallic rhodium films $[43,44]$. Both these routes require sophisticated equipment, expensive targets, and specially designed precursors, thereby increasing the fabrication cost substantially. On the other hand, the AACVD procedure used in this work is simple and cost effective where the metal loadings can be uniquely controlled just by the varying the deposition time. The catalytic performance is then governed by the orientation of the resulting nanostructures in space and, hence, related to the timecontrolled thickness of the film material. With all this simplicity, the metal loading can be controlled from the thickness of few microns to just a monolayer without any tedious synthesis mechanisms and deposition manipulations. Our group's expertise in AACVDbased fabrication of hierarchical nanostructures has resulted in the formation of exotic morphologies and distinguishable surface patterns [45-48]. In this work, a single-step AACVD has been applied for developing $\mathrm{Rh}$ thin film electrodes using a reaction-generated rhodium diethyldithiocaramate compound as a precursor. This is the first example of the fabrication of Rh films using AACVD and the novelty of the work lies in the generation of self-directed nano-forest morphologies without the use of any template. This custom-made fabrication procedure is less complicated while using minimal amount of precursor to grow thin films in a short span of time. In addition, the deposition parameters such as time and nature of substrate can be easily adjusted to generate a variety of novel Rh morphologies with controlled thicknesses. The impact of electrode morphology and thickness on the HER performance has been thoroughly studied and the most optimized structures with highest HER activity have been obtained.

\section{Results and Discussion}

\subsection{Optimization of the Deposition Process}

Fabrication of thin films via the CVD technique requires a proper precursor of adequate volatility and high thermal stability which leads to good quality thin films with well oriented nanostructures. A series of rhodium precursors were synthesized from CVD perspective. Only a few of those compounds possess enough thermal stability and volatility to yield rhodium thin films. Rhodium acetylacetonate $\mathrm{Rh}(\mathrm{acac})_{3}$ [43] and $\mathrm{CpRh}(\mathrm{CO})_{2}$ ( $\mathrm{Cp}=$ cyclopentadienyld) [49] have been recommended for atomic layer deposition (ALD), which is a variant of CVD. However, the use of AACVD only emphasizes the solubility of 
the precursor, rather than its thermal stability and volatility. Therefore, we modified and used a solution-based procedure. The preparation of the precursor solution was carried out by treating $\mathrm{RhCl}_{3}$ with $\mathrm{Na}\left(\mathrm{S}_{2} \mathrm{CNEt}_{2}\right)$ in methanol, and the resultant precipitates were immediately dissolved in toluene without characterizing the stoichiometry of the precursor. $\mathrm{RhCl}_{3}$ can be directly used as precursor because of its high solubility in methanol. However, the metal chlorides usually need higher temperature to release chloride ions, and thus can be co-deposited as impurity in the thin film at relatively lower temperatures. The slight modification to incorporate the reaction of $\mathrm{RhCl}_{3}$ and $\mathrm{Na}\left(\mathrm{S}_{2} \mathrm{CNEt}_{2}\right)$ in our solution-based approach helped to avoid chloride impurities in the resulting film. By using $\mathrm{Na}\left(\mathrm{S}_{2} \mathrm{CNEt}_{2}\right)$, the $\mathrm{Cl}^{-}$ions of rhodium are taken up by $\mathrm{Na}^{+}$ions whereas the dithiocarbamate group is completely burned off at a deposition temperature of $500{ }^{\circ} \mathrm{C}$. Thus, the procedure leads to the formation of pure metallic rhodium films without any sulfur or chloride incorporation. Fabrication of the films was carried out using an in-house AACVD setup at this deposition temperature and the conditions were optimized to get three sets of films at deposition time of 40,80 , and $120 \mathrm{~min}$.

\subsection{Structural Characterization}

Figure 1a shows the XRD patterns of rhodium (Rh) thin film deposited on Ti foil for 40, 80, and 120 min of deposition time, and the resulting film samples are denoted as Rh-40, Rh-80, and Rh-120, respectively. A comparative overview of XRD patterns is presented in Figure 1a. All three XRD patterns are dominated by crystalline reflections originated from Ti substrates which are represented by the symbol $(*)$. However, the XRD patterns distinctly appeared at $2 \theta$ positions of $41.0^{\circ}, 48.0^{\circ}, 70.0^{\circ}, 84.5^{\circ}$, and $89.2^{\circ}$ are due to (111), (200), (220), (311), and (222) planes of the Rh deposit, respectively. The crystallographic parameters ( $2 \theta$, peak intensity $(I)$, and d-spacing values) of the as-synthesized samples are in good agreement with those reported for cubic metallic rhodium (ICSD No. 6499). The intensity of the XRD reflections is discerned to increase with increasing deposition time, which is attributed to the increase in film thickness with the deposition time. For example, the XRD patterns centered at $41.0^{\circ}$ and $48.0^{\circ}$ rose continuously when the deposition time was increased from 40 to $120 \mathrm{~min}$ and reached to a good height in the case Rh120 sample. Thin Rh films were also made on a non-crystalline glass substrate under similar AACVD conditions, and the XRD patterns are shown in supporting information (Figure S1). The patterns support the XRD results of Rh obtained with Ti substrate. The well-resolved diffractions in each film sample suggest the presence of highly crystalline product. Moreover, the Rh-films showed a preferred orientation along (111) with increase in the deposition time, which is also consistent for all other identified patterns of $\mathrm{Rh}$ [50]. Further, presence of any crystalline impurity related to rhodium oxide or any other phase of metallic rhodium was not detected by the XRD. The XRD patterns of the as-prepared rhodium resembles rhodium films prepared by reported CVD procedures using different precursor compounds $[43,49]$.

X-ray photoelectron spectroscopy (XPS) analysis was applied to investigate the chemical oxidation state and purity of Rh- 80 film. Figure $1 \mathrm{~b}$ shows the highly resolved XPS spectrum of Rh $3 \mathrm{~d}$ having two binding energy peaks at $306.6 \mathrm{eV}$ and $310.3 \mathrm{eV}$, which are assigned to the $R h 3 d_{5 / 2}$ and $R h 3 d_{3 / 2}$, respectively. The binding energy difference $(\Delta E)$ between $R h 3 d_{5 / 2}$ and $R h 3 d_{3 / 2}$ is measured to be less than $4.0 \mathrm{eV}$, matching very well with the reported data of metallic rhodium in zero (0) oxidation state [51]. Thus, the XRD results combined with XPS data validate the formation of phase pure metallic rhodium thin films. 

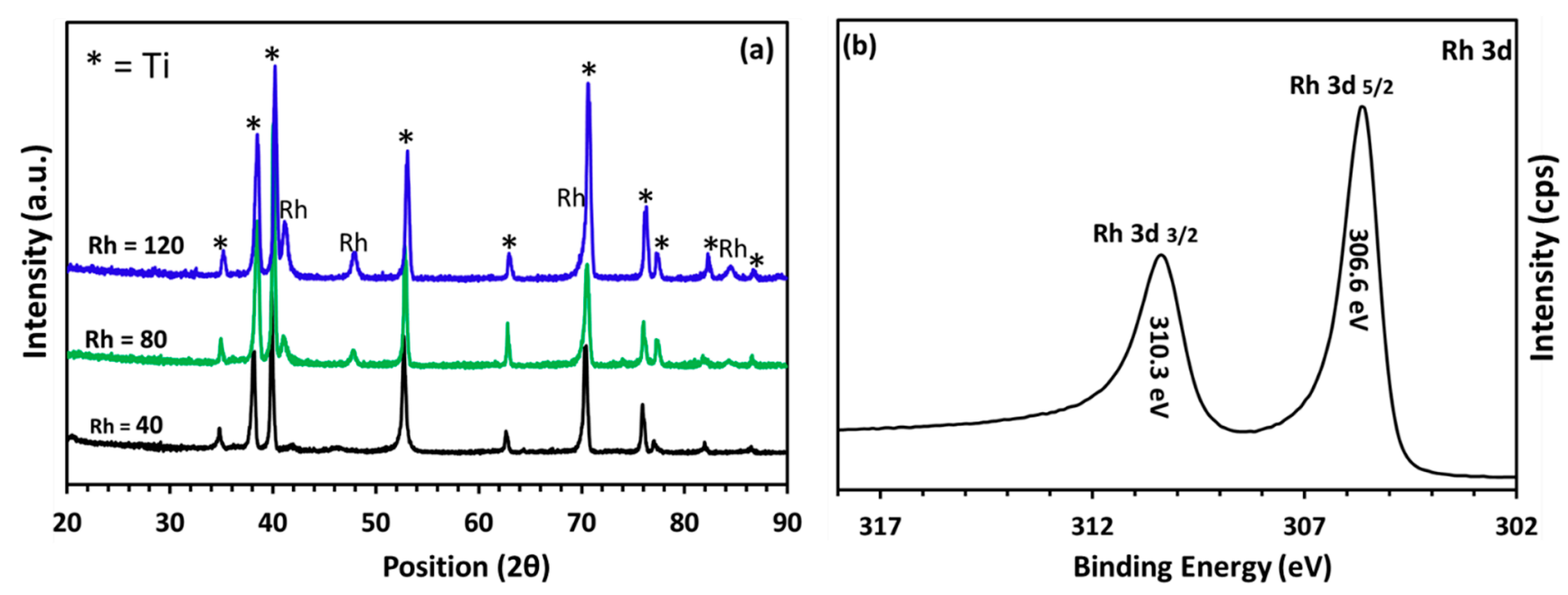

Figure 1. (a) XRD patterns of the rhodium (Rh) thin films prepared on Ti foil substrates for 40, 80, and 120 min (Rh-40, $\mathrm{Rh}-80$, and Rh-120) at $500{ }^{\circ} \mathrm{C}$, (b) high-resolution X-ray photoelectron spectroscopy (XPS) spectrum of Rh-80 indicating the elemental oxidation state of $\mathrm{Rh}$.

The evolution of Rh morphologies on two different surfaces of NF and Ti foil as well as with the change in deposition time is followed by FE-SEM. The low-magnification images, presented in supporting information (Figure S2), show continuous and steady growth patterns of the films on both types of substrates for all deposition times. No obvious voids and discontinuities in film structures are observed, and the morphological features tend to grow with increase in deposition time. The corresponding high magnification FE-SEM images of these films are shown in Figure 2. The morphologies observed on NF substrate are depicted in Figure $2 \mathrm{a}-\mathrm{c}$. In the first $40 \mathrm{~min}$ of deposition, the growth of vertically aligned objects similar to a view of plant field-like structure is observed. Moreover, branches and offshoots arising from these plants can be seen in Figure 2a. When the deposition time was increased to $80 \mathrm{~min}$, the plant-like structure transformed into features resembling a bunch of threads (Figure 2b). Further, the geometry of large-sized blooming flower was produced in film made in $120 \mathrm{~min}$, and a regular interconnected petal-like network is depicted in Figure 2c. When the deposition process was repeated on Ti substrate, growth of new morphology was discerned as indicated in Figure $2 \mathrm{~d}-\mathrm{f}$. The Rh nuclides appear after $40 \mathrm{~min}$ of deposition are interconnected with each other and develop a sheet-like structure on the surface of Ti. This sheet like structure grew into small-sized flower like morphology in the film developed for $80 \mathrm{~min}$ (Figure 2e). Further increase in deposition time (120 min) resulted in production of large-sized flowers with the cavities and channels between the petals opening up. The Rh morphologies observed on two substrate surfaces significantly differed from each other, which is attributed to the surface topographic difference of two substrate materials. The rough and uneven surface of NF provides different kinds of nucleation sites to the decomposed precursor as compared to the smooth and even surface of Ti. The different surface attributes of the substrates, therefore, led to the growth of different morphologies. Further, such microstructures are likely to possess different catalytic active sites and, hence, can exhibit different electrocatalytic performance towards the HER.

The films were further analyzed by energy-dispersive $X$-ray spectroscopy (EDX) to confirm the presence of Rh element. EDX spectra, Figure S3, clearly identify the signal related to Rh metal along with peaks emerging from substrate material (Ni and Ti). Peaks related to Au came from gold coating which was applied on film samples to enhance their conductivity for recording the high-quality FE-SEM images. 

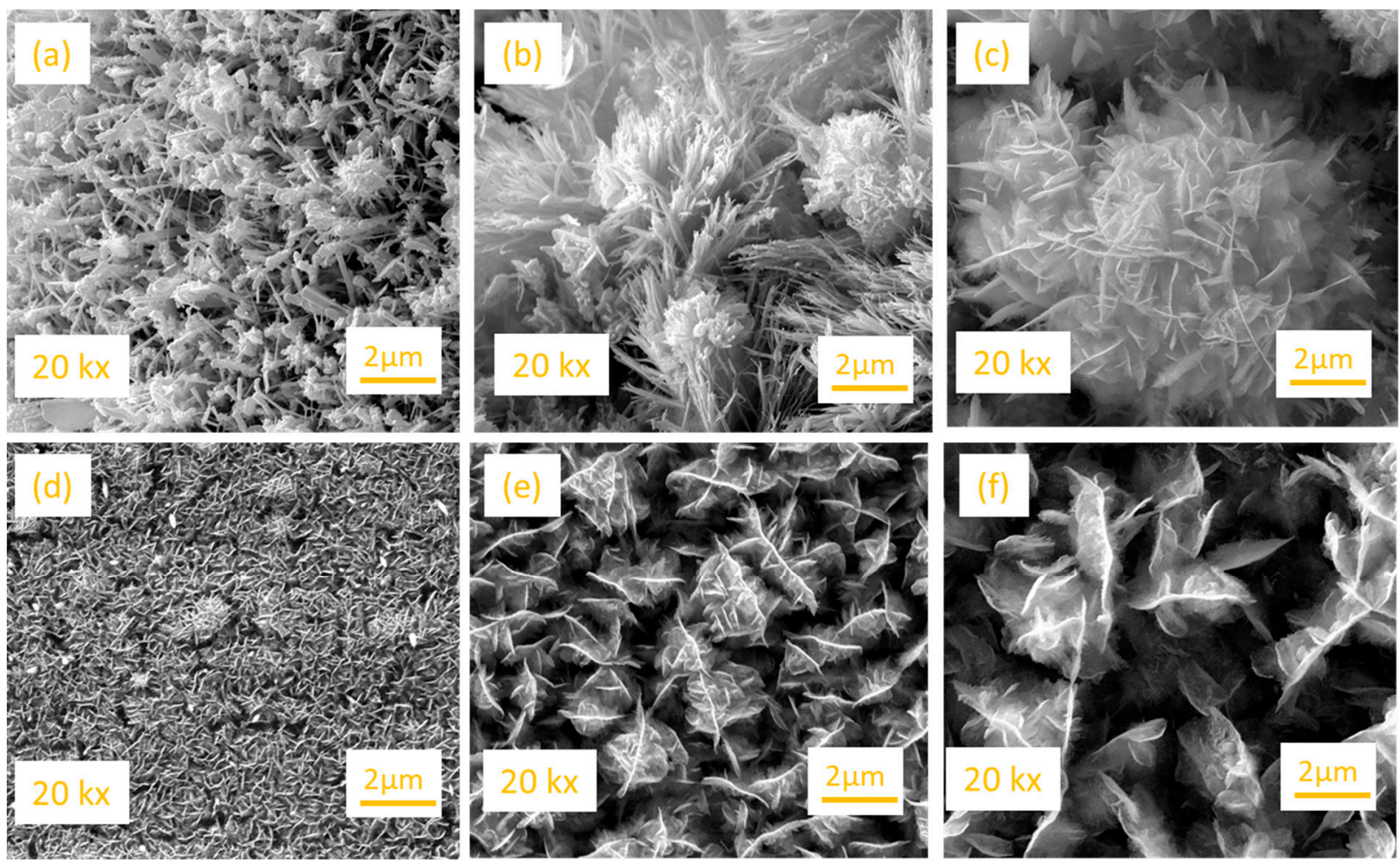

Figure 2. FE-SEM images of metallic Rh films, acquired from two different substrates (a-c) Ni foam and (d-f) Ti foil for deposition times of $40 \mathrm{~min}(\mathbf{a}, \mathbf{d}), 80 \mathrm{~min}(\mathbf{b}, \mathbf{e})$, and $120 \mathrm{~min}(\mathbf{c}, \mathbf{f})$.

\subsection{Evaluation of the Hydrogen Evolution Reaction (HER)}

The Rh films deposited on NF and Ti substrates were tested for the HER. The experiments were conducted under oxygen-free environment using $0.5 \mathrm{M} \mathrm{H}_{2} \mathrm{SO}_{4}$ as electrolyte. Previous studies have witnessed that deposition time has a huge impact on thin film microstructure, which ultimately influences the HER performances of the catalytic films $[27,28]$. At the same time, nature of the substrate plays an important role in exploring the full potential of material toward the HER. We, therefore, tested two different substrates, i.e., NF and Ti for all the films prepared. The HER performance of Rh/NF and Rh/Ti electrodes prepared after 40, 80, and 120 min of deposition time are shown in Figure 3. The electrocatalyst loading on Ti prepared in 40,80, and $120 \mathrm{~min}$ were determined to be $0.06,0.14$, and $0.16 \mathrm{mg} \mathrm{cm}^{-2}$, while on NF are $0.35,0.54$, and $0.61 \mathrm{mg} \mathrm{cm}^{-2}$. Figure $3 \mathrm{a}$ shows the linear scan voltammetry (LSV) profiles of the Rh films deposited on the NF substrate, including the response of bare NF electrode. As evident, the bare NF electrode, despite having its own catalytic activity, shows much lower current response for the HER in the absence of Rh deposits. Such finding indicates that the $\mathrm{Rh}$ in its nanostructured form has high intrinsic activity towards the proton reduction and the HER. Furthermore, the Rh films show high current density with quite low overpotentials, comparable to the commercially available materials such as $20 \% \mathrm{Pt} / \mathrm{C}[52,53]$. Both the current density and the overpotential values improved when the deposition time increased from $40 \mathrm{~min}$ to $80 \mathrm{~min}$. However, these values again diminished with Rh-120 film, while still being better than the Rh-40. For a current density of $100 \mathrm{~mA} \mathrm{~cm}{ }^{-2}$, the overpotentials for three different films, Rh/NF-80, Rh/NF-120, and Rh/NF-40, were noted to be 263, 294, and $317 \mathrm{mV}$, respectively. This can be related to the surface features of the films shown in FESEM data (Figure 2). The Rh-80 film had randomly oriented nano-threads and showed the highest HER activity. In comparison, Rh-40 was composed of loosely distributed vertically aligned nanorods while $\mathrm{Rh}-120$ had the blooming flower-like texture. It appears that $\mathrm{Rh}$ nano-threads present more catalytic active sites than the other two Rh assemblies and thus exhibit highest HER activity. In addition to the morphological features, the mass loading 
of the films can affect the charge transport properties and hence the HER performance. The thin film electrodes beyond the optimum mass loading can suffer from mass transport limitation, such as $\mathrm{H}^{+}$diffusion, diffusion of $\mathrm{H}_{2}$ gas from the active sites, etc. Moreover, the density of materials adds to the film thickness. Such an arrangement of features in Rh-80 film provide it the highest surface area and access points for the catalytic activity to proceed, thereby showing improved catalytic HER performance. The Rh/NF-80 film also showed a standard $10 \mathrm{~mA} \mathrm{~cm}^{-2}$ current density at an overpotential of $127 \mathrm{mV}$, which is better than many reported material combinations of Rh [54-56]. When the NF substrate was replaced by $\mathrm{Ti}$, the catalytic performance was further increased to be very close to $\mathrm{Pt} / \mathrm{C}$ based commercial electrodes- the $\mathrm{Rh} / \mathrm{Ti}-80$ requires $67 \mathrm{mV}$ while $\mathrm{Pt} / \mathrm{C}$ needs $39 \mathrm{mV}$ to produce $10 \mathrm{~mA} \mathrm{~cm}{ }^{-2}$. Between $\mathrm{Rh} / \mathrm{NF}$ and $\mathrm{Rh} / \mathrm{Ti}$ electrodes, i.e., the replacement of the NF substrate with Ti-foil, the latter exhibits substantially higher catalytic performance as shown in Figure $3 b$. The LSV curves shown here for different film depositions again indicate that the same performance pattern was followed in terms of deposition time. However, the Rh/Ti-80 electrode produces a $100 \mathrm{~mA} \mathrm{~cm}{ }^{-2}$ current density at $175 \mathrm{mV}$ (Figure 3c), which is $88 \mathrm{mV}$ less than that of the Rh/NF-80. Moreover, the overpotential required to generate $10 \mathrm{~mA} \mathrm{~cm}^{-2}$ current density is only $67 \mathrm{mV}$ for $\mathrm{Rh} / \mathrm{Ti}-80$ film, which is remarkable if we consider the ease of the electrode fabrication.
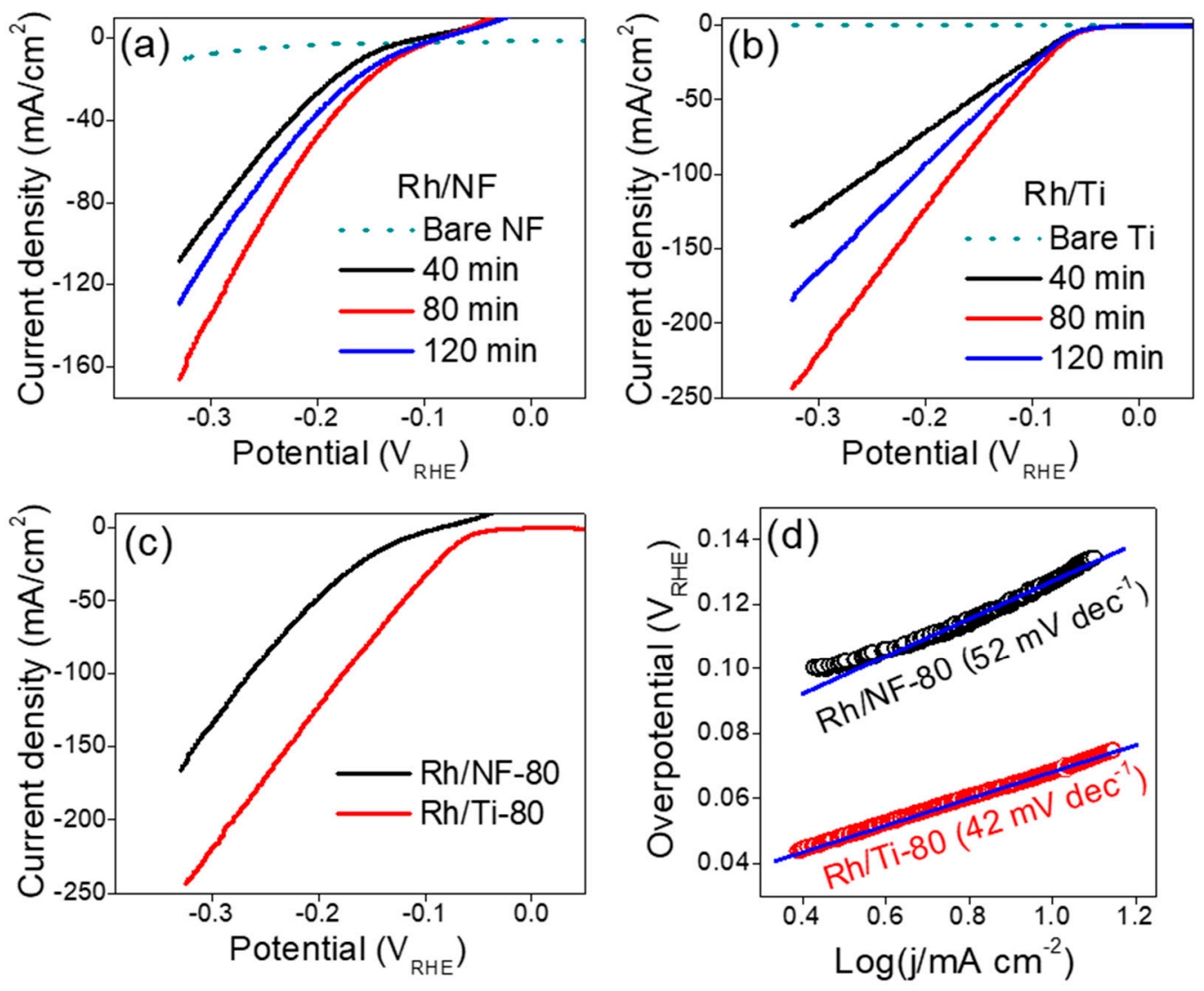

Figure 3. Linear sweep voltammetry (LSV) curves of Rh/nickel foam (NF) (a) and Rh/Ti (b) electrodes showing the effect of film deposition time (40, 80, and $120 \mathrm{~min}$ ) on the hydrogen evolution reaction (HER) performance, comparative LSVs of $\mathrm{Rh} / \mathrm{NF}$ and Rh/Ti prepared after 80 min deposition (c), and Tafel slopes (d).

To evaluate the kinetic ability of the films, Tafel slopes were obtained and compared by evaluating the linear region of LSV scans (Figure 3d). The respective Tafel values of Rh/Ti80 and Rh/NF-80 were calculated to be $42 \mathrm{mV} \mathrm{dec}^{-1}$ and $52 \mathrm{mV} \mathrm{dec}^{-1}$. These values clearly 
indicate that the $\mathrm{Rh} / \mathrm{Ti}-80$ electrode is capable of catalyzing the HER reaction faster than that of the Rh/NF-80, and the reaction seems to proceed through Heyrovsky mechanism:

$$
\mathrm{H}_{\mathrm{ads}}+\mathrm{H}_{(\mathrm{aq})+}+\mathrm{e}^{-} \rightarrow \mathrm{H}_{2}
$$

Moreover, the current density can be pushed to $\sim 250 \mathrm{~mA} \mathrm{~cm}^{-2}$ while the overpotential is still close to $300 \mathrm{mV}$, which is an industrially required factor to produce higher current density at the minimum possible electrical potential.

In addition to the morphological features of the films, the electrical conductivity and the catalytic ability can have a significant impact on the electrocatalytic performance. Electrical conductivity and turnover frequency (TOF) of Rh electrodes with the lowest overpotential (Rh/NF-80 and Rh/Ti-80) were investigated and correlated to the HER performance. The electrochemical impedance spectroscopic (EIS) technique was employed to study electrical resistance and surface charge transfer resistance. All the impedance experiments were carried out in the frequency range of $10^{5}-0.01 \mathrm{~Hz}$ with AC amplitude of $10 \mathrm{mV}$ in $0.5 \mathrm{M} \mathrm{H}_{2} \mathrm{SO}_{4}$. The EIS data were normalized with the geometrical area of the Ti and Ni electrode. Evolution in Nyquist plots (real vs. imaginary Z) as a function of overpotential $(\eta)$ was studied. The Rh/NF-80 electrode exhibited noticeably better electrical conductivity than that of Rh/Ti- 80 at all the applied $\eta$. The Nyquist plots of $\mathrm{Rh} / \mathrm{NF}-80$ and Rh/Ti- 80 measured by applying $\eta=0 \mathrm{mV}$ RHE are compared in Figure $4 \mathrm{a}$. As evident, the intrinsic electrical resistance of the $\mathrm{Rh} / \mathrm{Ti}-80$ electrode was substantially higher than that of the Rh/NF-80. In addition to intrinsic resistance, the surface charge transfer resistance $\left(R_{\mathrm{ct}}\right)$ of $\mathrm{Rh} / \mathrm{Ti}-80$ electrode was higher than that of Rh/NF-80 at all the applied overpotentials. For instance, the Nyquist plots of Rh/NF- 80 and Rh/Ti-80 obtained at $\eta=60 \mathrm{mV}_{\mathrm{RHE}}$ are compared in Figure $4 \mathrm{~b}$. The respective $R_{\mathrm{ct}}$ of $\mathrm{Rh} / \mathrm{NF}-80$ and $\mathrm{Rh} / \mathrm{Ti}-80$, determined from Figure $4 \mathrm{~b}$, were $\sim 0.7 \Omega$ and $5 \Omega$. Since the loading of $\mathrm{Rh}$ on NF substrate is higher than that of Ti, it might render better electrical conductivity. In addition, the better electrical conductivity and lower $R_{\mathrm{ct}}$ of Rh/NF-80 electrode can be attributed to better electrical conductivity rendered by bare NF. The real vs. imaginary impedance of bare NF and Ti, measured at $\eta=60 \mathrm{mV}_{\mathrm{RHE}}$, is shown in Figure $4 \mathrm{~b}$ inset. The findings clearly suggest that bare NF is much more electrically conductive than that of bare Ti foil, and can contribute in the enhancement of the electrical conductivity (and $R_{\mathrm{ct}}$ ) of $\mathrm{Rh} / \mathrm{NF}-80$ electrode.
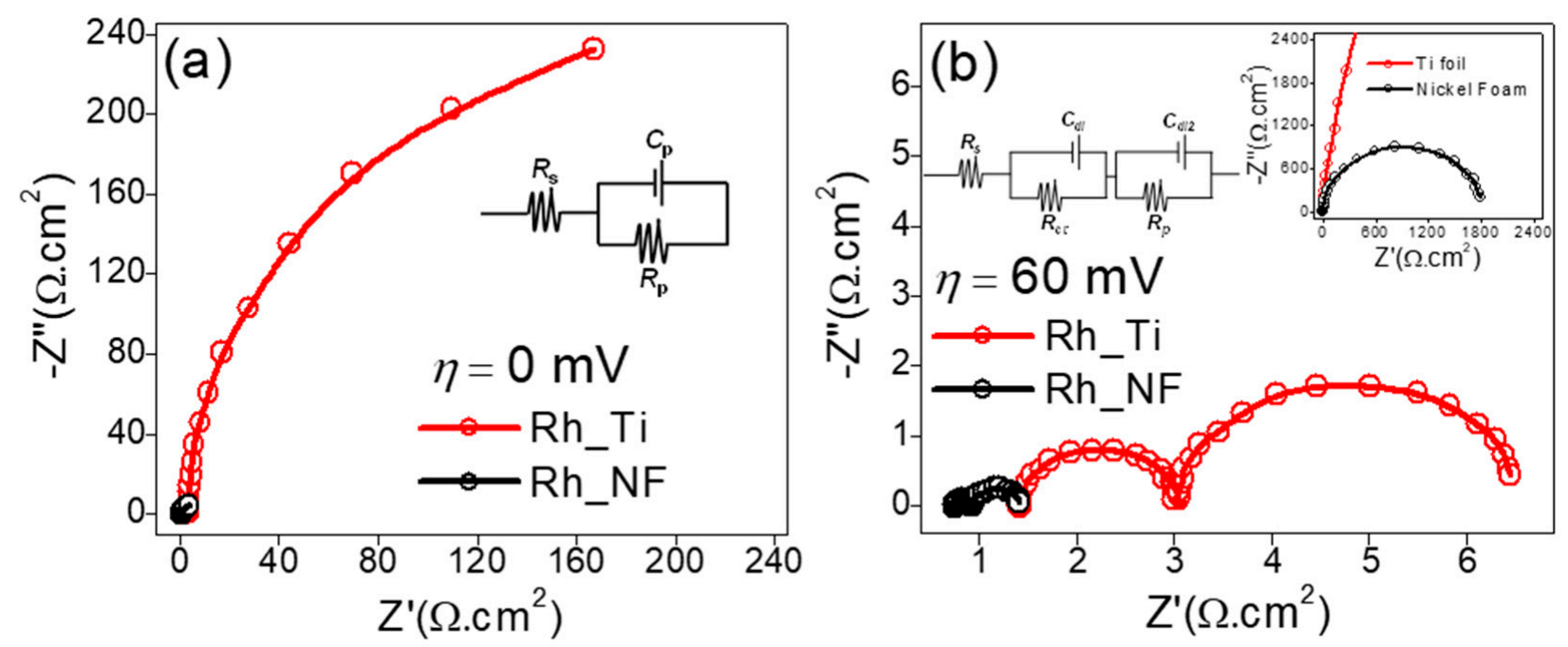

Figure 4. Nyquist plots of $\mathrm{Rh} / \mathrm{NF}$ and $\mathrm{Rh} / \mathrm{Ti}$ electrodes recorded at $\eta=0 \mathrm{mV}$ (a) and $\eta=60 \mathrm{mV}$. Nyquist plots of pristine (without electrocatalysts) NF and Ti (inset Figure (b)). $C_{p}=$ capacitive or electrical double layer element, $R_{s}$ and $R_{p}$ are resistive elements, $C_{d l}=$ electrical double layer capacitance, $R_{c t}=$ charge transfer resistance. 
In spite of lower electrical conductivity, Rh/Ti electrodes exhibited better HER performance. It seems reasonable to infer that the superior performance of the $\mathrm{Rh} / \mathrm{Ti}$ electrodes is essentially associated with the morphological properties, which governs the catalytic ability of the electrode. This was corroborated by estimating the number of catalytic sites $(N)$ and the turnover frequency (TOF). The $\mathrm{N}$ was calculated from cyclic voltammograms (CVs) recorded between $-0.2 \mathrm{~V}$ and $+0.6 \mathrm{~V}_{\mathrm{RHE}}$ at $\mathrm{pH}=7$. Phosphate buffer solution was used as the electrolyte. The voltammetry scans of Rh/NF- 80 and Rh/Ti- 80 are shown in Figure $5 a$. Assuming a redox reaction with one electron transfer and by using the Equation (1), the upper limit of active sites was approximated.

$$
N=\mathrm{Q} / 2 \mathrm{~F}
$$

where $\mathrm{Q}=$ voltametric charge, $\mathrm{F}=$ Faraday constant.

The active sites $(N)$ of Rh/NF-80 and Rh/Ti- 80 were estimated to be $3.2 \times 10^{-7}$ and $6.9 \times 10^{-9}$ mol. The superior $N$ recorded in case of the Rh/NF-80 rendered more accessible catalytic sites facilitating the adsorption and consequently the reaction of electroactive species which was presumably due to the porous texture of nickel foam. The turn-over frequency (TOF) was then calculated from $N$ using Equation (2):

$$
\mathrm{TOF}=\mathrm{JA} / 2 \mathrm{FN}
$$

where $\mathrm{J}=\mathrm{A} \mathrm{cm}^{-2}, \mathrm{~A}=$ geometric area of the Ti or Ni foam, $\mathrm{F}$ (Faraday's constant $)=96485 \mathrm{C} \mathrm{mol}^{-1}$, $\mathrm{N}=$ number of active sites $(\mathrm{mol})$, and the number 2 indicates the two electron involvement in the formation of one hydrogen molecule. The TOF profiles of Rh/NF-80 and Rh/Ti-80 obtained by plotting against $\eta$ are compared in Figure $5 \mathrm{~b}$. As can be seen, the Rh/Ti-80 electrode exhibits substantially higher TOF as compared to Rh/NF-80 electrode. For instance, at $\eta=260 \mathrm{mV}$, the TOF of Rh/NF-80 and Rh/Ti-80 electrodes are $1.1 \mathrm{~s}^{-1}$ and $37.3 \mathrm{~s}^{-1}$. This finding clearly suggests that Rh grown on Ti foil is significantly better in the catalytic ability per active sites than Rh deposited on NF. As a result, this combination proved more useful to be implemented in commercial water electrolyzers in the future.

The electrochemical stability of best performing $\mathrm{Rh} / \mathrm{Ti}-80$ electrode was investigated at a constant overpotential of $67 \mathrm{mV}$ in $0.5 \mathrm{M} \mathrm{H}_{2} \mathrm{SO}_{4}$ solution. The current-time profile and linear sweep voltammograms obtained before and after stability test are shown in Figure $6 \mathrm{a}, \mathrm{b}$, respectively.
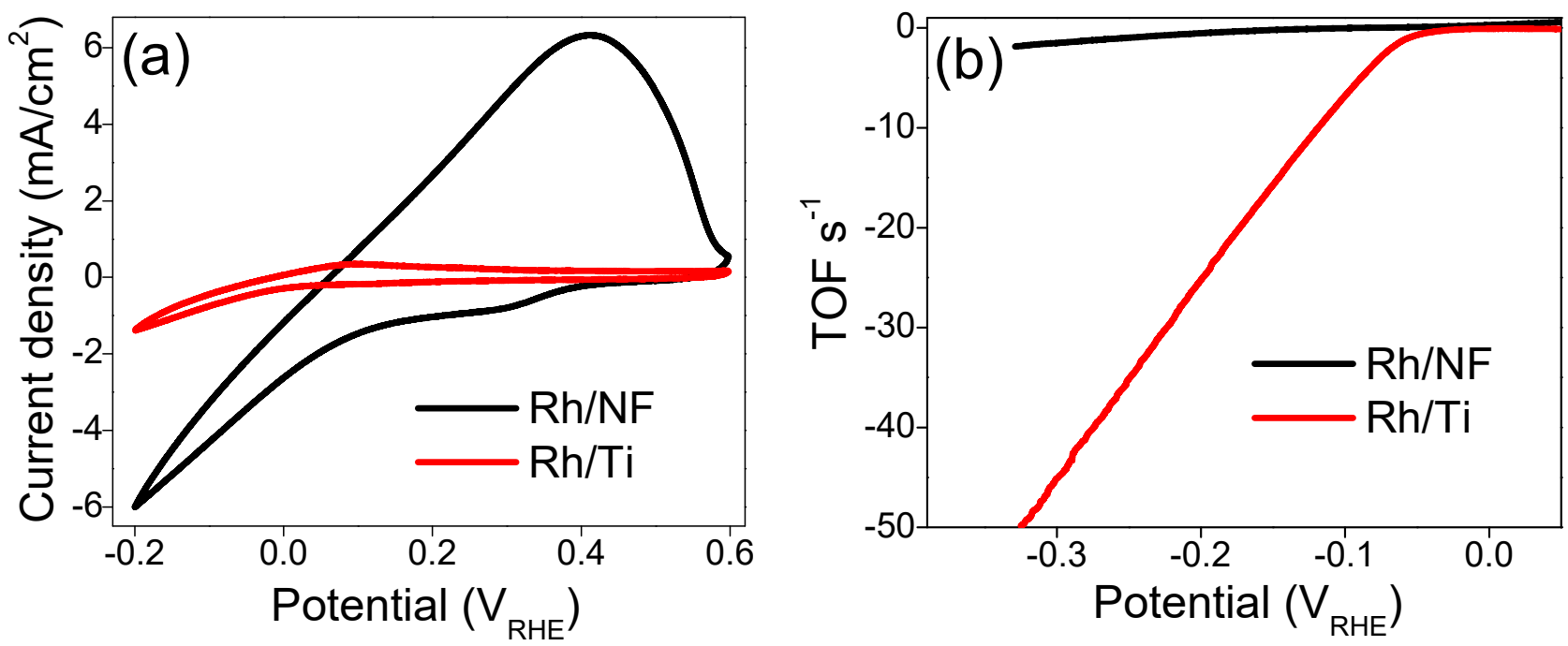

Figure 5. Comparative cyclic voltammetry (a) and corresponding turnover frequency (TOF) vs. $\eta$ (b) of Rh/NF-80 and $\mathrm{Rh} / \mathrm{Ti}-80$ electrodes. The CVs were measured between -0.2 and $0.6 \mathrm{~V}_{\mathrm{RHE}}$ at $\mathrm{pH}=7$ in a phosphate buffer solution with scan rate of $20 \mathrm{mV} \mathrm{s}^{-1}$. 

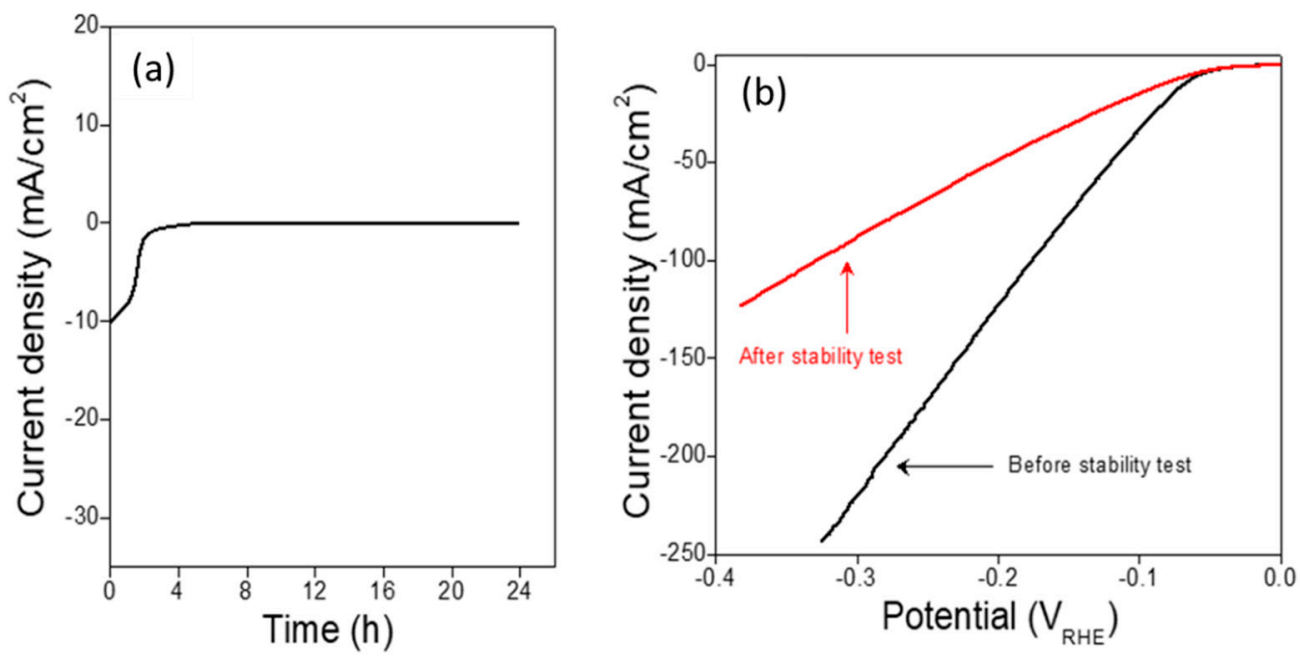

Figure 6. Current-time stability profile (a) and LSVs recorded before and after the stability test of $\mathrm{Rh} / \mathrm{Ti}-80$ (b).

The current-time profile, Figure $6 \mathrm{a}$, indicates that the current gradually reached zero after $\sim 3 \mathrm{~h}$, indicating the poor stability of $\mathrm{Rh} / \mathrm{Ti}-80$ electrode under the applied electrochemical conditions. After the stability test, the overpotential requirement of $\mathrm{Rh} / \mathrm{Ti}$ 80 electrode increased significantly. For instance, to produce $100 \mathrm{~mA} \mathrm{~cm}^{-2}$, fresh $\mathrm{Rh} / \mathrm{Ti}-80$ electrode requires $175 \mathrm{mV}$ while the spent electrode needed $328 \mathrm{mV}$ (Figure 6b). The team is planning to improve the electrochemical stability of Rh-based electrodes by compositing with other metals and nonmetals.

Finally, the HER activity of the as-prepared Rh nano-flower catalyst film was compared (Table 1) with rhodium and other noble metals developed through similar or different synthesis routes. As can be seen, the overpotential requirement of the as-fabricated films was much lower than those of Rh nanoparticles prepared by solvent reduction and etching methods. Yet, its HER performance was comparable to the rhodium sulfide, nanoporous $\mathrm{Pd}$, and $\mathrm{Pt}$ thin films. Tafel slopes and TOF values were also shown to be in the same range. However, this is first example of pure phase metallic Rhodium films produced via AACVD, a simple, rapid, and efficient protocol for material synthesis.

Table 1. Comparison of the HER performance of the as-prepared rhodium film with the other electrode consisting of noble metal group.

\begin{tabular}{|c|c|c|c|c|c|}
\hline Catalyst & Synthesis Approach & Electrode & $\begin{array}{l}\text { Overpotential } \eta_{50}(\mathrm{mV}) \\
@ 50 \mathrm{~mA} \mathrm{~cm}-2\end{array}$ & $\begin{array}{l}\text { Tafel Slope } \\
\left.(\mathrm{mV} \mathrm{dec})^{-1}\right)\end{array}$ & Reference \\
\hline Nanoporous Pd & AACVD & Nickel Foam & $\sim 65$ & $\sim 29$ & [28] \\
\hline Pt thin films & AACVD & Nickel foam & $\sim 100$ & $\sim 31$ & [27] \\
\hline $\mathrm{Rh}_{2} \mathrm{~S}_{3}$ & AACVD & Nickel foam & $\sim 72$ & 36 & [57] \\
\hline Rh nanoparticles & Solvent reduction method & Glassy carbon & $<250$ & 120 & [58] \\
\hline Rh nanoparticles & Etching & Glassy carbon & $<250$ & 40 & [59] \\
\hline Rh thin films & AACVD & Ti-foil & 67 & 42 & This work \\
\hline Rh thin films & AACVD & Nickel foam & 127 & 52 & This work \\
\hline
\end{tabular}

\section{Experimental}

\subsection{Chemicals for Precursor Synthesis}

Rhodium (III) chloride hydrate $\left(\mathrm{RhCl}_{3} \cdot \mathrm{H}_{2} \mathrm{O}\right)$ (Sigma-Aldrich, St. Louis, $\mathrm{MO}$, USA) and sodium diethyldithiocarbamte trihydrate $\left(\mathrm{NaS}_{2} \mathrm{CNEt}_{2} \cdot 3 \mathrm{H}_{2} \mathrm{O}\right)$ (Sigma Aldrich) were used as received for the synthesis of the deposition precursor. Methanol and toluene were purchased from Sigma Aldrich. 


\subsection{Aerosol-Assisted Chemical Vapor Deposition (AACVD) Experiments}

Thin films of metallic rhodium were prepared using two different metallic substrates, i.e., titanium foil (Ti) and nickel foam (NF). The details of the AACVD setup have been described in our earlier studies $[27,28]$. A schematic of custom-made AACVD is shown in Scheme 1. Briefly, the setup consists of a round bottom flask being immersed in a temperature-controlled water bath mounted above a piezoelectric modulator of an ultrasonic humidifier. The aerosol mist generated is transported into the reaction chamber, passing over a pre-heated substrate, thereby forming the required deposits. In a typical procedure, $\mathrm{RhCl}_{3} \cdot \mathrm{H}_{2} \mathrm{O}(80 \mathrm{mg}, 0.38 \mathrm{mmol})$ was reacted with $\left(\mathrm{NaS}_{2} \mathrm{CNEt}_{2} \cdot 3 \mathrm{H}_{2} \mathrm{O}\right)(172 \mathrm{mg}$, $0.76 \mathrm{mmol}$ ) in $10 \mathrm{~mL}$ of methanol to form red precipitates. The obtained precipitate was subsequently dissolved in $10 \mathrm{~mL}$ toluene and a clear red solution was obtained. The solution was kept under stirring for $20 \mathrm{~min}$ and was used as Rh precursor in AACVD.

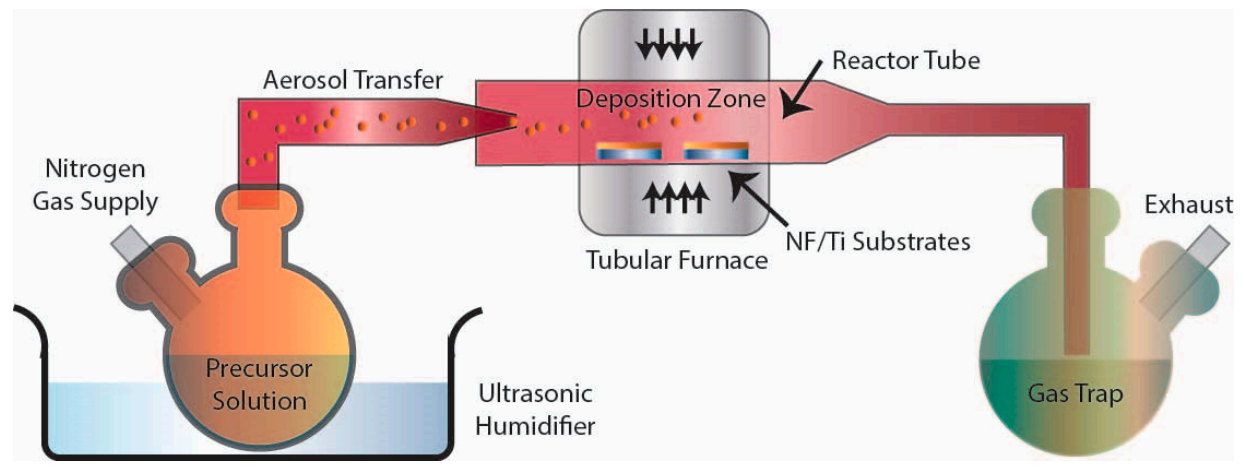

Scheme 1. A schematic of custom-made aerosol-assisted chemical vapor deposition (AACVD) setup used for the deposition of Rh thin films.

Before conducting the deposition, $\mathrm{Ti}$ and Ni substrates of sizes $(1.0 \mathrm{~cm} \times 2.0 \mathrm{~cm})$ were ultrasonically degreased and cleaned by treating with acetone and methanol solvents. The dried substrates were installed in the reactor tube and the temperature of tube furnace was raised to $500{ }^{\circ} \mathrm{C}$. After ten minutes, the humidifier was turned on to generate the aerosol mist from the Rh-precursor solution. The flow of mist towards tube furnace was facilitated with the aid of $\mathrm{N}_{2}$ gas $\left(99.99 \%\right.$ purity) at the controlled rate of $100 \mathrm{~cm}^{3} / \mathrm{min}$. The deposition was performed for different time periods, 40,80 , and $120 \mathrm{~min}$, to yield the films of modified morphological patterns and different thicknesses. The resulting films were found shiny black in color, homogenously lying down on the substrate surface.

\subsection{Instrumentation}

Powder XRD patterns of rhodium thin films were recorded on Rigaku MiniFlex X-ray diffractometer (Tokyo, Japan) with $\mathrm{Cu} \mathrm{K}_{\alpha 1}$ radiation $(\gamma=0.15416 \mathrm{~nm})$ operating at a current of $10 \mathrm{~mA}$ and an accelerating voltage of $30 \mathrm{kV}$. The chemical, elemental, and compositional analyses of the films were carried out by energy-dispersive X-ray spectroscopy (EDX, INCA Energy 200, Oxford Instruments, Abingdon, UK) and X-ray photoelectron spectroscopy (XPS, Thermos Scientific Escalab 250Xi spectrometer (Waltham, MA, USA) equipped with a monochromatic $\mathrm{Al} \mathrm{K} \alpha(1486.6 \mathrm{eV}) \mathrm{X}$-ray source, having a resolution of $0.5 \mathrm{eV})$. The ambient conditions of temperature were maintained during the XPS characterization, while the pressure was controlled at $5 \times 10^{-10}$ mbar. The spectra were referenced with adventitious $\mathrm{C} 1 \mathrm{~s}$ peak at $284.5 \mathrm{eV}$. The surface and cross-sectional images were obtained using field emission scanning electron microscope (FE-SEM, Lyra3, Tescan, Kohoutovice, Czech Republic) at an accelerating voltage of $20 \mathrm{kV}$.

\subsection{Electrocatalytic HER Studies}

The electrochemical HER studies were carried out using conventional three electrode configuration. The as-synthesized Rh thin films acted as working electrodes, while graphite 
rod and saturated calomel electrode $\left(\mathrm{Hg} / \mathrm{Hg}_{2} \mathrm{Cl}_{2}, \mathrm{SCE}\right)$ served as the counter and reference electrodes, respectively. The potential of the saturated calomel electrode was converted into the reversible hydrogen electrode (RHE) in all the data to have a meaningful comparison. The HER performance was evaluated by recording linear sweep voltammetry (LSV) scans (current density vs. potential). The LSV was performed in $0.5 \mathrm{M}$ sulfuric acid $\left(\mathrm{H}_{2} \mathrm{SO}_{4}\right)$ with a scan rate of $5 \mathrm{mV} \mathrm{s}^{-1}$. The current density was calculated by normalizing the current to the geometric surface area of the NF or Ti. Electrochemical impedance spectroscopy (EIS) was carried out under identical conditions; electrolyte $=0.5 \mathrm{M} \mathrm{H}_{2} \mathrm{SO}_{4}$, frequency range $=10^{5}-0.1 \mathrm{~Hz}$ with AC amplitude of $10 \mathrm{mV}$. All EIS plots were normalized to the geometric surface area of the working electrode.

\section{Conclusions}

Facile fabrication of metallic rhodium (Rh) film catalysts in the form of high surface area nano forests was accomplished on two substrates, namely nickel foam and titanium foil, via aerosol-assisted chemical vapor deposition within much shorter timespans (i.e., 40-120 $\mathrm{min}$ ) as compared to tedious wet chemical procedures taking up to days of synthetic reactions. The surface structures, the film thicknesses, and the purity of the films were characterized while relating those to the catalytic performance of the electrodes. Varying the deposition time facilitated surface morphology control of the Rh film catalysts where the sufficiently exposed high surface area film resulted in exhibiting the highest HER intrinsic activity. It is shown that the denser films of nano-flowers and nano-forests in combination with Ti substrate provide a much better performance towards the HER. These Rh films required only $67 \mathrm{mV}$ of overpotential to achieve $10 \mathrm{~mA} \mathrm{~cm}^{-2}$ of current density with low Tafel slope $\left(42 \mathrm{mV} \mathrm{dec}^{-1}\right)$ and high TOF $\left(37.3 \mathrm{~s}^{-1}\right)$. The current density can be further pushed beyond the values of $200 \mathrm{~mA} \mathrm{~cm}^{-2}$ while the overvoltage is still inside the industrial requirements. The electrochemical stability of Rh/NF electrodes are found to better than that $\mathrm{Rh} / \mathrm{Ti}$ electrodes. The stability findings indicate that more efforts should be exerted to improve the stability of Rh metal-based electrodes for the HER reaction.

Supplementary Materials: The following are available online at https:/ /www.mdpi.com/2073-434 4/11/3/338/s1, Figure S1: XRD patterns of the rhodium (Rh) thin films, Rh-40, Rh-80, and Rh-120, prepared on plain glass substrates for 40,80 , and $120 \mathrm{~min}$ of deposition time at $500{ }^{\circ} \mathrm{C}$ via AACVD, Figure S2: Low-magnification FE-SEM images of metallic Rh films, acquired from two different substrates (a1-c1) Ni foam and (d1-f1) Ti foil for deposition times of $40 \mathrm{~min}$ (a1) and (d1), $80 \mathrm{~min}$ (b1) and (e1), and $120 \mathrm{~min}$ (c1) and (f1), Figure S3: EDX spectra of Rh thin films deposition on Ni foam substrate for different deposition time of (a) $40 \mathrm{~min}$, (b) $80 \mathrm{~min}$, and (c) $120 \mathrm{~min}$, Figure S4: EDX spectra of $\mathrm{Rh}$ thin films deposition on Ti foil substrate for different deposition time of (a) $40 \mathrm{~min}$, (b) $80 \mathrm{~min}$, and (c) $120 \mathrm{~min}$.

Author Contributions: Conceptualization and methodology, M.A.E; software, A.A.; validation, M.Q., A.A., and A.R.; formal analysis, M.A.E and A.A.; investigation, M.Q.; resources, M.Q. and A.R.; writing-original draft preparation, M.A.E and A.R.; writing-review and editing, M.Q. and A.R.; supervision, M.Q and M.A.E.; project administration, M.A.E and A.R.; funding acquisition, A.R. and M.A.E. All authors have read and agreed to the published version of the manuscript.

Funding: This research was funded by Deanship of Scientific Research (DSR) at King Fahd University of Petroleum and Minerals (KFUPM), grant number "DF191037" and the APC was funded by grant number "DF191037".

Acknowledgments: M.A.E and A.R. would like to acknowledge the support provided by the Deanship of Scientific Research (DSR) at King Fahd University of Petroleum and Minerals (KFUPM) for funding this work through project No. DF191037. Authors are thankful to the research facilities at Center of Research Excellence in Nanotechnology (CENT) King Fahd University of Petroleum and Minerals, Saudi Arabia.

Conflicts of Interest: The authors state that there are no conflict of interest associated with this study and this manuscript's publication. 


\section{References}

1. Eftekhari, A. Electrocatalysts for hydrogen evolution reaction. Int. J. Hydrog. Energy 2017, 42, 11053-11077. [CrossRef]

2. Zhu, J.; Hu, L.; Zhao, P.; Lee, L.Y.S.; Wong, K.-Y. Recent advances in electrocatalytic hydrogen evolution using nanoparticles. Chem. Rev. 2019, 120, 851-918. [CrossRef]

3. Dubouis, N.; Grimaud, A. The hydrogen evolution reaction: From material to interfacial descriptors. Chem. Sci. 2019, 10, 9165-9181. [CrossRef] [PubMed]

4. Suliman, M.H.; Adam, A.; Li, L.; Tian, Z.; Siddiqui, M.N.; Yamani, Z.H.; Qamar, M. FeP/MoS 2 Enriched with Dense Catalytic Sites and High Electrical Conductivity for the Hydrogen Evolution Reaction. ACS Sustain. Chem. Eng. 2019, 7, 17671-17681. [CrossRef]

5. Suliman, M.H.; Adam, A.; Siddiqui, M.N.; Yamani, Z.H.; Qamar, M. Facile synthesis of ultrathin interconnected carbon nanosheets as a robust support for small and uniformly-dispersed iron phosphide for the hydrogen evolution reaction. Carbon 2019, 144, 764-771. [CrossRef]

6. Khoobi, A.; Ghoreishi, S.M.; Behpour, M.; Shaterian, M.; Salavati-Niasari, M. Design and evaluation of a highly sensitive nanostructure-based surface modification of glassy carbon electrode for electrochemical studies of hydroxychloroquine in the presence of acetaminophen. Colloids Surf. B Biointerfaces 2014, 123, 648-656. [CrossRef] [PubMed]

7. Nazir, R.; Fageria, P.; Basu, M.; Pande, S. Decoration of carbon nitride surface with bimetallic nanoparticles (Ag/Pt, Ag/Pd, and $\mathrm{Ag} / \mathrm{Au}$ ) via galvanic exchange for hydrogen evolution reaction. J. Phys. Chem. C. 2017, 121, 19548-19558. [CrossRef]

8. Yuan, M.; Xu, H.; Wang, Y.; Jin, L.; Wang, C.; Chen, C.; Wang, Y.; Shang, H.; Du, Y. Three-dimensional PdCuRu Alloy Porous Nanosheets as Efficient Electrocatalysts for Hydrogen Evolution Reaction in Varied Electrolytes. ChemElectroChem 2020, 7, 3135-3139. [CrossRef]

9. Paul, R.; Zhu, L.; Chen, H.; Qu, J.; Dai, L. Recent Advances in Carbon-Based Metal-Free Electrocatalysts. Adv. Mater. 2019, 31, 1806403. [CrossRef]

10. Li, C.; Baek, J.-B. Recent advances in noble metal (Pt, Ru, and Ir)-based electrocatalysts for efficient hydrogen evolution reaction. ACS Omega 2019, 5, 31-40. [CrossRef]

11. Wang, Q.; Ming, M.; Niu, S.; Zhang, Y.; Fan, G.; Hu, J.S. Scalable Solid-State Synthesis of Highly Dispersed Uncapped Metal (Rh, $\mathrm{Ru}$, Ir) Nanoparticles for Efficient Hydrogen Evolution. Adv. Energy Mater. 2018, 8, 1801698. [CrossRef]

12. Yin, H.-J.; Zhou, J.-H.; Zhang, Y.-W. Shaping well-defined noble-metal-based nanostructures for fabricating high-performance electrocatalysts: Advances and perspectives. Inorg. Chem. Front. 2019, 6, 2582-2618. [CrossRef]

13. Yao, Q.; Huang, B.; Zhang, N.; Sun, M.; Shao, Q.; Huang, X. Channel-Rich RuCu Nanosheets for pH-Universal Overall Water Splitting Electrocatalysis. Angew. Chem. Int. Ed. 2019, 58, 13983-13988. [CrossRef]

14. Shao, F.-Q.; Feng, J.-J.; Yang, Z.-Z.; Chen, S.-S.; Yuan, J.; Wang, A.-J. Cytosine assisted aqueous synthesis of AgPt hollow alloyed nanostructures as highly active electrocatalyst for ethylene glycol oxidation and hydrogen evolution. Int. J. Hydrog. Energy 2017, 42, 24767-24775. [CrossRef]

15. Levy, O.; Chepulskii, R.V.; Hart, G.L.; Curtarolo, S. The new face of rhodium alloys: Revealing ordered structures from first principles. J. Am. Chem. Soc. 2010, 132, 833-837. [CrossRef] [PubMed]

16. Teeriniemi, J.; Huisman, J.; Taskinen, P.; Laasonen, K. First-principles modelling of solid Ni-Rh (nickel-rhodium) alloys. J. Alloys Compd. 2015, 652, 371-378. [CrossRef]

17. Matsagar, B.M.; Hsu, C.-Y.; Chen, S.S.; Ahamad, T.; Alshehri, S.M.; Tsang, D.C.; Wu, K.C.-W. Selective hydrogenation of furfural to tetrahydrofurfuryl alcohol over a Rh-loaded carbon catalyst in aqueous solution under mild conditions. Sustain. Energ. Fuels 2020, 4, 293-301. [CrossRef]

18. Bhuvanendran, N.; Balaji, S.; Zhang, W.; Xu, Q.; Pasupathi, S.; Su, H. Improved activity and stability of Ag-Rh network-like nanoalloy as support-free electrocatalyst for oxygen reduction in alkaline fuel cells. J. Renew. Sustain. Energy 2020, $12,044301$. [CrossRef]

19. Arandiyan, H.; Wang, Y.; Scott, J.; Mesgari, S.; Dai, H.; Amal, R. In situ exsolution of bimetallic Rh-Ni nanoalloys: A highly efficient catalyst for CO2 methanation. ACS Appl. Mater. Interfaces 2018, 10, 16352-16357. [CrossRef]

20. Grass, M.E.; Zhang, Y.; Butcher, D.R.; Park, J.Y.; Li, Y.; Bluhm, H.; Bratlie, K.M.; Zhang, T.; Somorjai, G.A. A reactive oxide overlayer on rhodium nanoparticles during $\mathrm{CO}$ oxidation and its size dependence studied by in situ ambient-pressure $\mathrm{X}$-ray photoelectron spectroscopy. Angew. Chem. Int. Ed. 2008, 47, 8893-8896. [CrossRef] [PubMed]

21. Feng, J.-J.; Chen, L.-X.; Ma, X.; Yuan, J.; Chen, J.-R.; Wang, A.-J.; Xu, Q.-Q. Bimetallic AuPt alloy nanodendrites/reduced graphene oxide: One-pot ionic liquid-assisted synthesis and excellent electrocatalysis towards hydrogen evolution and methanol oxidation reactions. Int. J. Hydrog. Energy 2017, 42, 1120-1129. [CrossRef]

22. Yin, X.P.; Wang, H.J.; Tang, S.F.; Lu, X.L.; Shu, M.; Si, R.; Lu, T.B. Engineering the coordination environment of single-atom platinum anchored on graphdiyne for optimizing electrocatalytic hydrogen evolution. Angew. Chem. Int. Ed. 2018, 57, 9382-9386. [CrossRef]

23. Cheng, N.; Stambula, S.; Wang, D.; Banis, M.N.; Liu, J.; Riese, A.; Xiao, B.; Li, R.; Sham, T.-K.; Liu, L.-M. Platinum single-atom and cluster catalysis of the hydrogen evolution reaction. Nat. Commun. 2016, 7, 13638. [CrossRef] [PubMed]

24. Sait, E.; Beelders, W.; Bradley, S.J.; Kroon, R.; Laufersky, G.; Andersson, M.; Nann, T. Platinum Terpyridine Metallopolymer Electrode as Cost-Effective Replacement for Bulk Platinum Catalysts in Oxygen Reduction Reaction and Hydrogen Evolution Reaction. ACS Sustain. Chem. Eng. 2017, 5, 10206-10214. 
25. Ji, J.; Zhang, Y.; Tang, L.; Liu, C.; Gao, X.; Sun, M.; Zheng, J.; Ling, M.; Liang, C.; Lin, Z. Platinum single-atom and cluster anchored on functionalized MWCNTs with ultrahigh mass efficiency for electrocatalytic hydrogen evolution. Nano Energy 2019, 63, 103849. [CrossRef]

26. Han, X.; Wu, X.; Deng, Y.; Liu, J.; Lu, J.; Zhong, C.; Hu, W. Ultrafine Pt nanoparticle-decorated pyrite-type CoS 2 nanosheet arrays coated on carbon cloth as a bifunctional electrode for overall water splitting. Adv. Energy Mater. 2018, 8, 1800935. [CrossRef]

27. Ehsan, M.A.; Suliman, M.H.; Rehman, A.; Hakeem, A.S.; Al Ghanim, A.; Qamar, M. Fabrication of platinum thin films for ultra-high electrocatalytic hydrogen evolution reaction. Int. J. Hydrog. Energy 2020, 45, 15076-15085. [CrossRef]

28. Ehsan, M.A.; Suliman, M.H.; Rehman, A.; Hakeem, A.S.; Yamani, Z.H.; Qamar, M. Direct deposition of a nanoporous palladium electrocatalyst for efficient hydrogen evolution reaction. New J. Chem. 2020, 44, 7795-7801. [CrossRef]

29. Muench, F.; Neetzel, C.; Kaserer, S.; Brötz, J.; Jaud, J.-C.; Zhao-Karger, Z.; Lauterbach, S.; Kleebe, H.-J.; Roth, C.; Ensinger, W. Fabrication of porous rhodium nanotube catalysts by electroless plating. J. Mater. Chem. 2012, 22, 12784-12791. [CrossRef]

30. Falini, G.; Gualandi, A.; Savoia, D. Rhodium/graphite-catalyzed hydrogenation of carbocyclic and heterocyclic aromatic compounds. Synthesis 2009, 14, 2440-2446.

31. Maegawa, T.; Akashi, A.; Sajiki, H. A mild and facile method for complete hydrogenation of aromatic nuclei in water. Synlett 2006, 9, 1440-1442. [CrossRef]

32. Vermisoglou, E.C.; Romanos, G.E.; Karanikolos, G.N.; Kanellopoulos, N.K. Catalytic NOx removal by single-wall carbon nanotube-supported Rh nanoparticles. J. Hazard. Mater. 2011, 194, 144-155. [CrossRef] [PubMed]

33. Beyer, H.; Köhler, K. NOx removal by rhodium catalysts supported on carbon nanotubes: Evidence for the stoichiometric reduction of NO2 and NO by the carbon support. Appl. Catal. B 2010, 96, 110-116. [CrossRef]

34. Kanuru, V.K.; Humphrey, S.M.; Kyffin, J.M.; Jefferson, D.A.; Burton, J.W.; Armbrüster, M.; Lambert, R.M. Evidence for heterogeneous Sonogashira coupling of phenylacetylene and iodobenzene catalyzed by well defined rhodium nanoparticles. Dalton Trans. 2009, 7602-7605. [CrossRef] [PubMed]

35. Sathe, B.R. Methanol electro-oxidation on nanostructured rhodium network. Energy Environ. 2015, 4, 196-200. [CrossRef]

36. Sathe, B.R.; Balan, B.K.; Pillai, V.K. Enhanced electrocatalytic performance of interconnected Rh nano-chains towards formic acid oxidation. Energy Environ. Sci. 2011, 4, 1029-1036. [CrossRef]

37. Biacchi, A.J.; Schaak, R.E. The solvent matters: Kinetic versus thermodynamic shape control in the polyol synthesis of rhodium nanoparticles. ACS Nano 2011, 5, 8089-8099. [CrossRef]

38. Mizuno, T.; Matsumura, Y.; Nakajima, T.; Mishima, S. Effect of support on catalytic properties of Rh catalysts for steam reforming of 2-propanol. Int. J. Hydrog. Energy 2003, 28, 1393-1399. [CrossRef]

39. Han, Y.-F.; Kahlich, M.; Kinne, M.; Behm, R. CO removal from realistic methanol reformate via preferential oxidationperformance of a $\mathrm{Rh} / \mathrm{MgO}$ catalyst and comparison to $\mathrm{Ru} / \gamma-\mathrm{Al}_{2} \mathrm{O}_{3}$, and $\mathrm{Pt} / \gamma-\mathrm{Al}_{2} \mathrm{O}_{3}$. Appl. Catal. B 2004, 50, $209-218$. [CrossRef]

40. Kašpar, J.; Fornasiero, P.; Hickey, N. Automotive catalytic converters: Current status and some perspectives. Catal. Today 2003, 77, 419-449. [CrossRef]

41. Sathe, B.R. Rhodium nanoparticle-carbon nanosphere hybrid material as an electrochemical hydrogen sensor. RSC Adv. 2013, 3, 5361-5365. [CrossRef]

42. N’Diaye, J.; Poorahong, S.; Hmam, O.; Izquierdo, R.; Siaj, M. Facile synthesis rhodium nanoparticles decorated single layer graphene as an enhancement hydrogen peroxide sensor. J. Electroanal. Chem. 2017, 789, 85-91. [CrossRef]

43. Aaltonen, T.; Ritala, M.; Leskelä, M. ALD of rhodium thin films from Rh (acac) 3 and oxygen. Electrochem. Solid-State Lett. 2005, 8, C99. [CrossRef]

44. Lu, J.-P.; Chu, P.W.; Raj, R.; Gysling, H. Ultrahigh vacuum chemical vapor deposition of rhodium thin films on clean and TiO2-covered Si (111). Thin Solid Films 1992, 208, 172-176. [CrossRef]

45. Ehsan, M.A.; Hakeem, A.S.; Sharif, M.; Rehman, A. Direct Deposition of Amorphous Cobalt-Vanadium Mixed Oxide Films for Electrocatalytic Water Oxidation. ACS Omega 2019, 4, 12671-12679. [CrossRef] [PubMed]

46. Ehsan, M.A.; Hasan, M.M.; Islam, T.; Hossain, M.D.; Aziz, M.A.; Ahammad, A.S. Fabrication of nanostructured Pd thin films using aerosol-assisted chemical vapor deposition for the nonenzymatic electrochemical detection of $\mathrm{H}_{2} \mathrm{O}_{2}$. ACS Appl. Electron. Mater. 2019, 1, 417-429. [CrossRef]

47. Ehsan, M.A.; Sohail, M.; Jamil, R.; Hakeem, A.S. Single-Step Fabrication of Nanostructured Palladium Thin Films via AerosolAssisted Chemical Vapor Deposition (AACVD) for the Electrochemical Detection of Hydrazine. Electrocatalysis 2019, 10, $214-221$. [CrossRef]

48. Joya, K.S.; Ehsan, M.A.; Sohail, M.; Yamani, Z.H. Nanoscale palladium as a new benchmark electrocatalyst for water oxidation at low overpotential. J. Mater. Chem. A 2019, 7, 9137-9144. [CrossRef]

49. Marsh, E.P.; Uhlenbrock, S. Solvated Ruthenium Precursors for Direct Liquid Injection of Ruthenium and Ruthenium Oxide and Method of Using Same. Google Patents 2003.

50. Swanson, H.E.; Fuyat, R.K.; Ugrinic, G.M. International Centre for Diffraction Data, Powder Diffraction File, Entry. US Natl. Bur. Stand. Circ. 1996, 5, 685.

51. Abe, Y.; Kato, K.; Kawamura, M.; Sasaki, K. Rhodium and rhodium oxide thin films characterized by XPS. Surf. Sci. Spectra 2001, 8, 117-125. [CrossRef] 
52. Adam, A.; Suliman, M.H.; Dafalla, H.; Al-Arfaj, A.R.; Siddiqui, M.N.; Qamar, M. Rationally dispersed molybdenum phosphide on carbon nanotubes for the hydrogen evolution reaction. ACS Sustain. Chem. Eng. 2018, 6, 11414-11423. [CrossRef]

53. Adam, A.; Suliman, M.H.; Siddiqui, M.N.; Yamani, Z.H.; Merzougui, B.; Qamar, M. Interconnected hollow cobalt phosphide grown on carbon nanotubes for hydrogen evolution reaction. ACS Appl. Mater. Interfaces 2018, 10, 29407-29416. [CrossRef] [PubMed]

54. Kim, J.; Kim, H.; Ahn, S.H. Electrodeposited rhodium phosphide with high activity for hydrogen evolution reaction in acidic medium. ACS Sustain. Chem. Eng. 2019, 7, 14041-14050. [CrossRef]

55. Smiljanic, M.; Rakocevic, Z.; Maksic, A.; Strbac, S. Hydrogen evolution reaction on platinum catalyzed by palladium and rhodium nanoislands. Electrochim. Acta 2014, 117, 336-343. [CrossRef]

56. Shen, W.; Ge, L.; Sun, Y.; Liao, F.; Xu, L.; Dang, Q.; Kang, Z.; Shao, M. Rhodium nanoparticles/F-doped graphene composites as multifunctional electrocatalyst superior to $\mathrm{Pt} / \mathrm{C}$ for hydrogen evolution and formic acid oxidation reaction. ACS Appl. Mater. Interfaces 2018, 10, 33153-33161. [CrossRef] [PubMed]

57. Ehsan, M.A.; Adam, A.; Rehman, A.; Hakeem, A.S.; Isab, A.A.; Qamar, M. Morphologically controlled rapid fabrication of rhodium sulfide (Rh2S3) thin films for superior and robust hydrogen evolution reaction. Sustain. Energy Fuels 2021, 5, 459-468. [CrossRef]

58. Yang, F.; Zhao, Y.; Du, Y.; Chen, Y.; Cheng, G.; Chen, S.; Luo, W. A Monodisperse Rh2P-Based Electrocatalyst for Highly Efficient and $\mathrm{pH}$-Universal Hydrogen Evolution Reaction. Adv. Energy Mater. 2018, 8, 1703489. [CrossRef]

59. Zhu, L.; Lin, H.; Li, Y.; Liao, F.; Lifshitz, Y.; Sheng, M.; Lee, S.-T.; Shao, M. A rhodium/silicon co-electrocatalyst design concept to surpass platinum hydrogen evolution activity at high overpotentials. Nat. Commun. 2016, 7, 12272. [CrossRef] 